\title{
Analysis of Students' Errors in Solving Word Problems Viewed from Mathematical Resilience
}

\author{
Agus Haerani', Khusnul Novianingsih ${ }^{2}$, Turmudi ${ }^{3}$ \\ 1,2,3 Departemen of Mathematics Education, Universitas Pendidikan Indonesia, Indonesia \\ 1agushaerani@upi.edu, ${ }^{2}$ khusnuln@yahoo.com, ${ }^{3}$ turmudi@upi.edu
}

\begin{abstract}
Article History:

Received : 21-01-2021

Revised : 01-04-2021

Accepted : 01-04-2021

Online : :17-04-2021

Keywords:

Mathematical resilience;

Students' errors;

Word problems.

Many students in the world have difficulty in solving word problems, including students in Indonesia. TIMSS has shown that only eight percent of Indonesian participants are able to solve word problems, this result is hugely lower than the international average of 18 percent. One of the factors that cause students' errors in solving word problems is mathematical resilience. Thus, this study aims to analyze students' misconceptions in solving word problems viewed by their mathematical strength. This study was conducted for sixth-grade students in one of the elementary schools in Bandung. This study was qualitative descriptive research. In this study, there were four steps: selecting the word problems, answering the issues, filling out a mathematical resilience questionnaire, and interviewing. Students were encouraged to respond to a three-word question within 30 minutes, filling out a mathematical resilience questionnaire followed by the interview. This study showed that the students' errors in solving word problems were including comprehension, transformation, and process skill errors. Based on mathematical resilience, students with a low level of resilience predominantly carried out comprehension errors. In contrast, students with a moderate level of resilience more dominant made transformation errors. Meanwhile, students with high resilience completed more questions correctly, although several students seemed to have made process skills errors. This study's limitation is the data obtained online so that the respondents completed the instrument exceeds the given time. Further researches are suggested to conduct directly in the classroom to maximize the accuracy of the study.
\end{abstract}

\section{A. INTRODUCTION}

Word problems are considered one of the most challenging mathematics topics, so they are commonly used as educational literature. De Coete et al., 1989 (Seifi et al., 2012) the mathematics word problem is known as an instrument of development students' abilities and talents in solving math problems. Most of the mathematics word problem relates to real life situations with mathematical concepts. In fact, such problems assist students in using their mathematical knowledge to solve their everyday problems. According to Fairbairn, 1993 (Bates \& Wiest, 2004) word problems have several important functions in mathematics, namely providing questions that challenge students to be applied to various mathematical thinking situations, besides that word problems can also be an efficient means of connecting mathematical thinking to the real life. 
Solving word problems is a significant difficulty for many students. Mullis et al., 2008 (Jupri \& Drijvers, 2016) revealed that the results of a report on the 2007 Trends in International Mathematics and Science Study (TIMSS) showed that students in Indonesia had difficulty in solving word problems. It can be seen from a small number of students who were able to complete word problems are lower than international students' percentage average. Difficulties in solving word problems resulted in increased stress and anxiety in students so that they became phobia of word problems (Khoshaim, 2020).

One of the sources of difficulty in solving word problems in reading comprehension and the meaning of the keywords used in math word problems (Vula et al., 2017). The ability of students to understand problems is the factor most reported by the teacher as the cause of student difficulty in solving word problems (Pearce et al., 2011). Previous research (VileniusTuohimaa et al., 2008) has revealed that mathematics word problem-solving performance and reading comprehension ability are related to overall reasoning skills. According to Clements (Riastuti et al., 2017), students' most errors include comprehension, transformation, and students' tendency to make carelessness.

Many factors cause students' errors. According to Munasinghe (Tong \& Loc, 2017), several factors that cause student errors are psychological fan drive guiding errors from parents or family, and students' unconsciousness. Identification of student errors is needed to determine the obstacles that cause students to be unable to solve problems. According to Newman (Jha, 2012), there are five obstacles that a person needs to overcome in solving math problems, namely reading, comprehension, transformation, process skills, and encoding. (Abdullah et al., 2015) revealed that the errors occur because the students fail to understand and explain what is required by the question. Students frequently make errors in comprehension, transformation, process skills and encoding. Other authors (Junaedi et al., 2015) identified language and carelessness as the obstacles that need to be overcome. According to (Veloo et al., 2015) the most reason given for errors being made is a lack of understanding, the procedure being forgotten, negligence in writing down information from questions, carelessness and guesswork.

Apart from cognitive factors, affective factors also influence learning achievement. One of the attitudes that contribute an essential role in learning achievement is not giving up, surviving in solving problems, and having confidence in their abilities. This attitude is called resilience (Gumelar \& Kusumah, 2019). Previous research revealed that mathematical strength could improve students' learning achievement (Zanthy, 2018). Based on this background, this study aims to analyze students' errors in solving word problems in terms of mathematical resilience.

\section{B. METHODS}

This research uses descriptive research with a qualitative approach. The instrument used in this study is a three-item word problem followed by interviews and a resilience questionnaire with positive and negative statements. The subjects of this study were 17 sixth grade elementary school students. Data were collected by testing the word problems instrument test, then checking and categorizing the student answer sheets. Categorization was conducted by analyzing errors using Newman's Error Procedure (NEP), which consists of 
five errors in solving word problems: Reading, Comprehension, Transformation, Process Skills, and Encoding (Jha, 2012).

The researchers also conducted interviews with six students to obtain information about the students' difficulties in solving word problems in terms of the mathematical resilience category. Data collection was also driven by filling out a mathematical resilience questionnaire adapted to (Sumarmo et al., 2019). This study's resilience questionnaire consisted of four indicators with 25 statement items; each statement from the resilience scale had four answer options. Namely Very Often (SS), Often (S), Rarely (J), and Very Rare (SJ). The results were analyzed to classify students' resilience levels, namely high, medium, and low, after being tested. The categorization is based on Siffudin (Kurnia et al., 2018), which explains that the resilience scale categorization step in the study is to find the lowest and the highest score, to find the ideal mean (M), which is a half (highest score + lowest score), and look for the standard deviation (SD), which is $1 / 6$ (highest score - lowest score).

Based on the mentioned steps, then the calculation of the resilience scale is presented in Table 1.

Table 1. The Category of Mathematical Resilience

\begin{tabular}{ccc}
\hline Limit (interval) & Limit (interval) & Category \\
\hline $\mathrm{X}<\mathrm{M}-1 \mathrm{SD}$ & $\mathrm{X}<50$ & Low Resilience \\
$\mathrm{M}-1 \mathrm{SD} \leq \mathrm{X}<\mathrm{M}+1 \mathrm{SD}$ & $50 \leq \mathrm{X}<75$ & Medium Resilience \\
$\mathrm{X} \geq \mathrm{M}+1 \mathrm{SD}$ & $\mathrm{X} \geq 75$ & High Resilience \\
\hline
\end{tabular}

\section{RESULT AND DISCUSSION}

Students' errors are often found in mathematics, particularly in solving word problems. This study uses Newman's Error Procedure (NEP) to identify student errors. Analysis of students' errors was only conducted toward worksheets containing the incorrect answer; some students could resolve word problems, but the rest of the students more visible to make mistakes include comprehension, transformation, and process skills error. While it is an empty answer is not regarded as a mistake. A summary of the analysis of students' misconceptions in solving word problems based on Newman's Error Procedure (NEP) can be seen in Table 2.

Table 2. Summary Analysis of Student Errors

\begin{tabular}{lccccccc}
\hline & \multicolumn{2}{c}{ Problem 1 } & \multicolumn{2}{c}{ Problem 2 } & \multicolumn{2}{c}{ Problem 3 } & $\begin{array}{c}\text { Average } \\
\text { Percentage }\end{array}$ \\
\cline { 2 - 8 } & $\mathrm{N}$ & $\%$ & $\mathrm{~N}$ & $\%$ & $\mathrm{~N}$ & $\%$ & $\%$ \\
\hline Correct Answer & 12 & 71 & 6 & 35 & 3 & 18 & 41 \\
No Answer & 0 & 0 & 0 & 0 & 0 & 0 & 0 \\
Reading (R) & 0 & 0 & 0 & 0 & 0 & 0 & 0 \\
Comprehension (C) & 4 & 24 & 5 & 29 & 5 & 29 & 28 \\
Transformation (T) & 1 & 5 & 3 & 18 & 6 & 35 & 19 \\
Process Skill (P) & 0 & 0 & 3 & 18 & 3 & 18 & 12 \\
Encode (E) & 0 & 0 & 0 & 0 & 0 & 0 & 0 \\
\hline
\end{tabular}

The results of the student error analysis shown in Table 2. Based on Table 2, it can be seen that 17 students were tried to solve the three-word problems given, even though only $41 \%$ 
were able to answer the word problems correctly. Based on the resulting study, the most errors that were made by students were in the comprehension section of $28 \%$, the transformation error of $19 \%$, and the error of processing skills by $12 \%$. Meanwhile, the aspects of reading and encoding errors were not obtained in this study.

The researchers found that the error made by students were including the aspects of comprehension, transformation, and process skills. This finding emphasized previous research (Wijaya et al., 2014) that comprehension errors and transformation errors are the most dominant errors made by students. Meanwhile, process skill errors and encoding errors are rare because students make mistakes in the comprehension aspect and transformation aspect, so that it is unable to solve the problem correctly.

To find out the information of students' error based on high, medium, and low mathematical resilience categories, subsequent researchers analyzed the data filling the questionnaire resilience mathematically. The distribution of student resilience categories is shown in Table 3.

Table 3. Results of A Mathematical Resilience Questionnaire

\begin{tabular}{ccc}
\hline Resilience Category & Student Code & $\begin{array}{c}\text { The Number of } \\
\text { Students }\end{array}$ \\
\hline Low & S6, S7, S8, S12, S13, S17 & 6 \\
Moderate & S1, S3, S4, S5, S9, S10, S14, S15 & 8 \\
High & S2, S11, S16 & 3 \\
\hline
\end{tabular}

Based on the distribution of the students 'mathematical resilience questionnaire results in Table 3, then the aspects of the students' problems were compared by taking two sample data from each category of resilience. Students' errors in solving word problems in terms of mathematical stability are shown in Table 4.

Table 4. The Results of The Student Error Analysis in Terms of Mathematical Resilience

\begin{tabular}{ccccc}
\hline & \multicolumn{4}{c}{ Students' Error } \\
\hline Resilience Category & Student Code & Problem 1 & Problem 2 & Problem 3 \\
\hline \multirow{3}{*}{ Low } & S6 & $\mathrm{C}$ & $\mathrm{C}$ & $\mathrm{C}$ \\
& $\mathrm{S} 7$ & - & $\mathrm{T}$ & $\mathrm{C}$ \\
\multirow{3}{*}{ High } & S4 & $\mathrm{T}$ & $\mathrm{T}$ & $\mathrm{T}$ \\
& $\mathrm{S} 15$ & - & - & $\mathrm{P}$ \\
& $\mathrm{S} 11$ & - & - & $\mathrm{P}$ \\
& $\mathrm{S} 16$ & - & $\mathrm{P}$ & - \\
\hline
\end{tabular}

Student errors viewed from mathematical resilience can be seen in Table 4, where students predominantly commit comprehension errors with a low resilience level. In contrast, transformation errors are mostly committed by students with a moderate level of resilience. Meanwhile, students with high stability completed more questions correctly. This is in line with previous research that students with high strength can recognize and apply mathematical ideas in everyday life. Students with high resilience can understand word problems and write mathematical symbols that match sentences in word problems (Rohmah et al., 2020). Some students with more strength to make mistakes in the aspect of skill process for careless. Examples of comprehension errors made by students with low resilience are shown in Figure 1. 


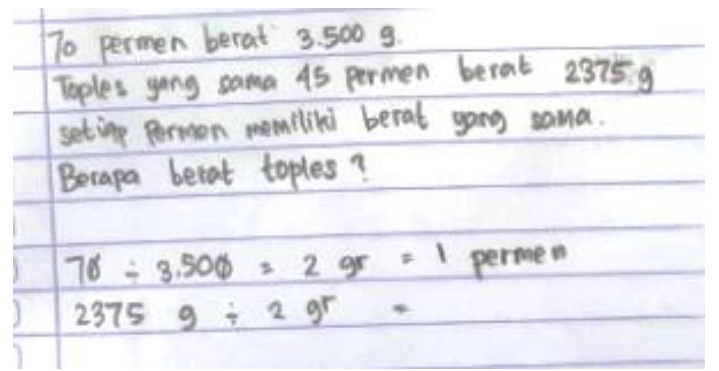

Figure 1. Student's Answer Sheet with Comprehension Errors in Problem 2.

Figure 1 shows the answer sheet S6 in solving word problem 2, where S6 performs error comprehension. According to Clements in (Riastuti et al., 2017), comprehension errors occur when students can read all the statements on the problem that must be solved but do not understand the meaning of all words so that students are unable to continue the problemsolving procedure further. S6 can identify problems by rewriting what is known and asked about them, but S6 cannot understand it correctly. Based on the interview results, S6 does not understand the sentence the same jar is used for several perms with the same weight, S6 does not know that the importance of 3,500 grams is the pot's weight plus the weight of 70 candies. Several other students with low resilience also made the same mistake in the comprehension aspect. As a result, when students find it difficult, they will stop because they are afraid of making mistakes and cannot solve the problem to completion. A similar condition occurs in a study that reveals that students with low resilience tend to be afraid of making mistakes and do not have the fighting power to solve problems (Suri \& Herman, 2020).

The type of student error that often occurs is transformation errors. Transformation errors occur when students understand the meaning of all the words in a problem but cannot compile a mathematical model used to solve a problem (Wijaya et al., 2014). Figure 2 shows the transformation error that S4 performed with moderate resilience in solving word problem 1.

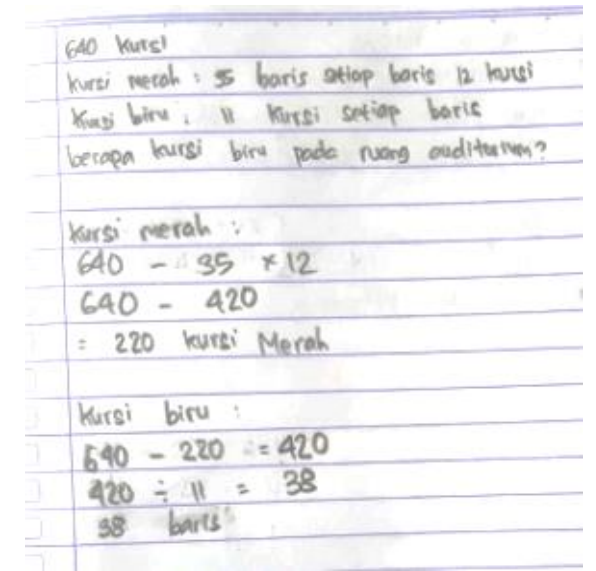

Figure 2. The Student's Answer Sheet with Transformation Errors in Problem 1.

Figure 2 shows the transformation error, where S4 can read and understand the meaning of all sentences in the problem but has difficulty performing the sequence of count operations. Besides, S4 also saw errors in compiling a mathematical model. Based on the interview results, S4 felt confident and capable of solving word problems even though he was confused about which arithmetic operation should be used. 44 realized it had made a mistake in counting the 
number of red seats, multiplying the rows by the seats in each row. Apart from S4, similar transformation errors were also made by five other students S1, S3, S5, S10, and S14, who had moderate resilience to the three-word problems given. Even though these students had difficulties, they still tried to solve the word problems.

Furthermore, the students' errors that were observed in this study were errors in processing skills. Students made processing error skills with moderate and high resilience. This error occurs because students are not careful in performing mathematical numeracy operations. The error in the process of students' skills in solving word problems is shown in Figure 3.

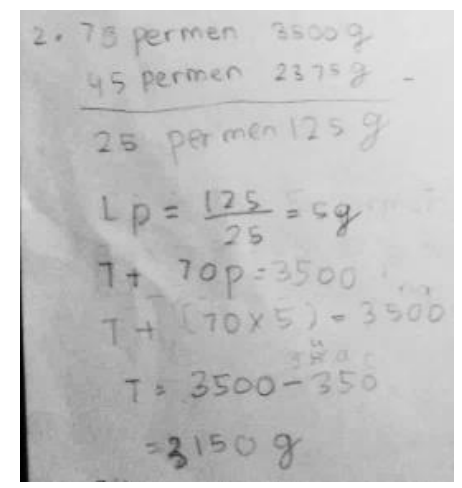

Figure 3. Student Answer Sheets with Process Skill Errors on Problem 2.

Process skill errors occur when performing incorrect mathematical procedures. According to Clements (Riastuti et al., 2017), error processing skills occur when students can identify problems well and carry out the sequence of count operations needed to solve problems but do not use procedures correctly. In Figure 3, students with the high resilience category made mistakes in calculating the reduction. Based on the interview results, S16 admitted his mistake because he was not careful when calculating the difference in the weight of the candy. S16 can identify the problem well, but S16 is not aware that it has made a mistake in the calculation.

\section{CONCLUSION AND SUGGESTIONS}

This study shows students' dominant mistakes in solving math word problems, namely comprehension, transformation, and process skill errors. The predominant error that students make is comprehension errors of 28 percent, the transformation error of 19 percent, and the processing skills error of 12 percent. Based on mathematical resilience, students with a low level of resilience predominantly carried out comprehension errors. In contrast, students with a moderate level of resilience more dominant made transformation errors. Meanwhile, students with high resilience completed more questions correctly, although several students seemed to have made process skills errors. This research's limitation is that data colletion is done online so that many factors affected the instrument testing results. We suggest that further research can be done face-to-face. Based on the study results, the level of resilience is related to student errors in solving word problems. Finally, we suggest that further research needs to be done analysis determine the relationship between students 'mathematical strength and mathematical abilities. 


\section{ACKNOWLEDGEMENT}

The writer would like to show high gratitude to the teachers for the constructive comments and suggestions while writing this paper and for the students who have supported and participated in this research.

\section{REFERENCES}

Abdullah, A. H., Abidin, N. L. Z., \& Ali, M. (2015). Analysis of students' errors in solving Higher Order Thinking Skills (HOTS) problems for the topic of fraction. Asian Social Science, 11(21), 133-142. https://doi.org/10.5539/ass.v11n21p133

Bates, E. T., \& Wiest, L. R. (2004). Impact of Personalization of Mathematical Word Problems on Student Performance. Mathematics Educator, 14(2), 17-26.

Gumelar, G. R., \& Kusumah, Y. S. (2019). Mathematical Communication Ability Based on Mathematical Resilience. 673-682.

Jha, S. K. (2012). Mathematics performance of primary school students in Assam (India): An analysis using Newman Procedure. International Journal of Computer Applications in in Engineering Sciences, II(I), 17-21.

Junaedi, I., Suyitno, A., Sugiharti, E., \& Eng, C. K. (2015). Disclosure Causes of Students Error in Resolving Discrete Mathematics Problems Based on NEA as A Means of Enhancing Creativity. International Journal of Education, $7(4), \quad 31$. https://doi.org/10.5296/ije.v7i4.8462

Jupri, A., \& Drijvers, P. (2016). Student difficulties in mathematizing word problems in Algebra. Eurasia Journal of Mathematics, Science and Technology Education, 12(9), 2481-2502. https://doi.org/10.12973/eurasia.2016.1299a

Khoshaim, H. B. (2020). Mathematics teaching using word-problems: Is it a phobia! International Journal of Instruction, 13(1), 855-868. https://doi.org/10.29333/iji.2020.13155a

Kurnia, H. I., Royani, Y., Hendiana, H., \& Nurfauziah, P. (2018). Analisis Kemampuan Komunikasi Matematik Siswa Smp Di Tinjau Dari Resiliensi Matematik. Jurnal $\begin{array}{llll}\text { Pembelajaran Matematika Inovatif, } & \text { 933-940. }\end{array}$ https://journal.ikipsiliwangi.ac.id/index.php/jpmi/article/view/ 1597/288

Pearce, D. L., Bruun, F., \& Skinner, K. (2011). International Electronic Journal of Mathematics Education - IIJM $\Sigma$ Vol.8, No.1. 8(1).

Riastuti, N., Mardiyana, M., \& Pramudya, I. (2017). Students' Errors in Geometry Viewed from Spatial Intelligence. Journal of Physics: Conference Series, 895(1). https://doi.org/10.1088/1742-6596/895/1/012029

Rohmah, S., Kusmayadi, T. A., \& Fitriana, L. (2020). Mathematical connections ability of junior high school students viewed from mathematical resilience. Journal of Physics: Conference Series, 1538(1). https://doi.org/10.1088/1742-6596/1538/1/012106

Seifi, M., Haghverdi, M., \& Azizmohamadi, F. (2012). Recognition of Students' Difficulties in Solving Mathematical Word Problems from the Viewpoint of Teachers. Journal of Basic and Applied Scientific Research, 2(3).

Sumarmo, U., Hendriana, H., Ahmad, \& Yuliani, A. (2019). Tes Dan Skala Matematika Bernuansa High Order Thinking Skill.

Suri, A., \& Herman, T. (2020). How are the contributions of mathematics resilience for developing attitude rubric to assess mathematics learning? Journal of Physics: Conference Series, 1521(3). https://doi.org/10.1088/1742-6596/1521/3/032055

Tong, D. H., \& Loc, N. P. (2017). Students' errors in solving mathematical word problems and their ability in identifying errors in wrong solutions. European Journal of Education Studies, 3(6), 226-241. https://doi.org/10.5281/zenodo.581482 
Veloo, A., Krishnasamy, H. N., \& Wan Abdullah, W. S. (2015). Types of student errors in mathematical symbols, graphs and problem-solving. Asian Social Science, 11(15), 324334. https://doi.org/10.5539/ass.v11n15p324

Vilenius-Tuohimaa, P. M., Aunola, K., \& Nurmi, J. E. (2008). The association between mathematical word problems and reading comprehension. Educational Psychology, 28(4), 409-426. https://doi.org/10.1080/01443410701708228

Vula, E., Avdyli, R., Berisha, V., Saqipi, B., \& Elezi, S. (2017). The impact of metacognitive strategies and self-regulating processes of solving math word problems. International Electronic Journal of Elementary Education, 10(1), 49-59. https://doi.org/10.26822/iejee.2017131886

Wijaya, A., van den Heuvel-Panhuizen, M., Doorman, M., \& Robitzsch, A. (2014). Difficulties in solving context-based PISA mathematics tasks: An analysis of students' errors. Mathematics Enthusiast, 11(3), 555-584.

Zanthy, L. S. (2018). Kontribusi Resiliensi Matematis Terhadap Kemampuan Akademik Mahasiswa Pada Mata Kuliah Statistika Matematika. Mosharafa: Jurnal Pendidikan Matematika, 7(1), 85-94. https://doi.org/10.31980/mosharafa.v7i1.344 